\title{
Male sexual dysfunction in patients with chronic end-stage renal insufficiency and in renal transplant recipients
}

\author{
Michele Antonucci ${ }^{1}$, Giuseppe Palermo ${ }^{1}$, Salvatore Marco Recupero ${ }^{1}$, Riccardo Bientinesi ${ }^{1}$, \\ Fabrizio Presicce $^{2}$, Nazario Foschi ${ }^{1}$, PierFrancesco Bassi ${ }^{1}$, Gaetano Gulino ${ }^{1}$ \\ ${ }^{1}$ Department of Urology Clinic, Catholic University of S. Heart, Rome, Italy; \\ ${ }^{2}$ Urology, Policlinico S. Andrea, "La Sapienza" University, Rome, Italy.
}

\begin{abstract}
Summary Materials and Methods: The study was conducted from December 2011 to December 2012 on 95 patients between the ages of 20 and 65 years: 44 of which had been undergoing dialysis for over a year and 51 of whom had undergone kidney transplants more than 6 months before. Comorbidities were carefully recorded, erectile function was evaluated the with IIEF5 questionnaire and serum levels of total testosterone / free and prolactin were tested at early morning (7 AM). To assess the relationship between erectile dysfunction (ED) and clinical laboratory tests, Student's t-test statistical (quantitative variables), chi-square (qualitative variables), the uni and multivariate analysis were used.

Results: In patients undergoing dialysis and in recently transplanted patients a higher instance of ED was found (70\% and $65 \%$ of cases respectively). Amongst dialyzed patients, patients aged over 50 suffer from ED more frequently. Patients aged over 50 s represent $61 \%$ of the total number of patients suffering from ED, and just $31 \%$ of patients not suffering from $\mathrm{ED},(p=0.006)$;

Hyperprolactinemia was found in $23 \%$ and $20 \%$ of both groups respectively. Fifty nine \% of the dialyzed patients presented values of testosterone serum levels of less than $250 \mathrm{ng} / \mathrm{dl}$ with a significant difference between those who were suffering from ED and those who were not (65\% of ED patients vs. 46\%, of patients not affected from ED $p=0.019$ ). This was found in only $37 \%$ of transplanted patients and there does not appear to be a statistically significant correlation with the onset of $\operatorname{ED}(p=0.12)$. In patients over the age of 50, diabetes and a condition of hypotestosteronemia were significantly correlated with ED at univariate and multivariate analyses.

Conclusions: The ED in patients with end stage chronic kidney failure (CKF) continues to have a strong prevalence, either in the patients who are undergoing dialysis or in those who have received transplants. In literature this issue is not sufficiently considered if not at all. Hypotestosteronemia is a risk factor for the onset of ED in end stage CKF patients. A significantly lower prevalence of hypogonadism among dialyzed patents and transplant recipients suggests that renal transplantation may be protective for the sexual capabilities of these patients.
\end{abstract}

KEY WORDS: Chronic renal failure; Kidney transplant; Erectile dysfunction; Hypogonadism; Pathophysiology; Risk factors.

Submitted 18 January 2015; Accepted 30 April 2015

\section{INTRODUCTION}

Patients with end-stage chronic kidney failure (CKF) who undergo hemodialysis experience a significant deterioration in their quality of life, due both to a treatment requiring patients to attend dialysis sessions of 3-4 hours duration 3 days a week, and for the comorbidity associated with it. Among comorbidities, it is important to highlight erectile dysfunction due to its high frequency. In 1975, the first scientific studies documenting a close link between erectile dysfunction and chronic renal failure came to light (1). Erectile dysfunction (ED) is an inability to obtain or maintain an erection sufficient for satisfactory sexual activity. With the examination of several studies, its prevalence in this group of patients becomes apparent with a leveling off between 50 and $80 \%(1,2)$. Several factors may contribute to the onset of erectile dysfunction and its progression over time. These could include: abnormalities in the neuro-endocrine control system of the hypothalamic-pituitary-gonadal axis; secondary hyperparathyroidism; peripheral neuropathy; changes in smooth muscle of the corpora cavernosa of the penis, structural alterations of the arterial wall, damage of the veno-occlusive cavernosal mechanism, drug therapies consequential to CKF, stress and depression.

\section{Pathophysiology of erectile dysfunction}

in chronic renal failure

Numerous scientific evidence shows that the pulsatile release of gonadotrophic hormones in uremic patients is dramatically compromised until reaching a stage of clear hypogonadism (3).

In the plasma of patients with severe CKF, a decrease in the concentration of testosterone and increased levels of FSH and LH it is often noted (4). The decrease of concentration of testosterone in plasma is attributed to several mechanisms: increased testosterone excretion during the dialysis treatment (5), reduction of its production by the Leydig cells (6), poor response to gonadotropin stimulation probably induced, at least in part, by cytokine changes resulting from the chronic systemic disease. Low levels of testosterone stimulate a feedback mechanism with the secretion of LH, whose concentration is further elevated as a result of its reduced renal excretion. FSH levels are high because of the atrophy of

No conflict of interest declared. 
the Sertoli cells, normally responsible for its inhibition through the secretion of inhibin peptide (7).

Hyperprolactinemia was present in $25-57 \%$ of male patients with CKF and was indicated by some authors as a possible associated cause of impotence, hypogonadism and decreased libido (8). Hyperprolactinemia interferes with normal gonadal response to gonadotropins, thus resulting in a reduction in testicular steroidogenesis. The reasons for the occurence of this remain disputed. Erectile dysfunction may, however, be the earliest clinical manifestation of diabetes based on autonomic neuropathy. Diabetes is in fact the most frequent factor which determines a condition of end-stage chronic renal failure. Studies of tissue biopsy samples of uremic patients with diabetes and erectile dysfunction documented a weakening of neurogenic and endothelial mechanisms that allows the relaxation of smooth muscles of the corpora cavernosa (9). In those patients the simultaneous diagnosis of neurogenic bladder supports a neuropathic etiology of erectile dysfunction (10). The peripheral neuropathies are the most frequent, in particular a sensorymotor polyneuropathy that appears with numbness, burning pain, and a reduction or disappearance of deep tendon reflexes. Restless legs syndrome is frequent, characterized by continuous movement of the legs during sleep and caused by impaired neuromuscular conduction velocity. The autonomic nervous system may also be compromised, leading to alterations in blood pressure control and erectile dysfunction on a neuropathic basis. The basis of the neuropathy is probably a block of nerve transmission mediated by so-called "uremic toxins" (urea, creatinine, parathyroid hormone, myoinositol and $\beta 2$ microglobulin). In particular, some substances with a molecular weight between 300 and 12,000 Dalton are suspected of being responsible for the neuropathy. Studies have also shown a slowing of nerve conduction in the segments not affected clinically. In patients with chronic kidney disease an abnormal metabolism of carbohydrates, lipids and proteins is often observed. Due to these reasons, and also to the state of inflammation that accompanies the chronic kidney diseases, the uremic patient is particularly predisposed to atherosclerosis and therefore to ischemic disease especially in the coronary artery, but also in the arterial penile district, determining an artery based erectile dysfunction.

Diabetes together with hypertension, another condition extremely common in dialyzed patients, often determines a significant acceleration of atherosclerotic processes and therefore a vascular based erectile dysfunction (11). In a large proportion of end-stage CKF patients (78\%), in fact, an occlusion was found in blood vessels in the pelvic arteries and their tributaries (12).

A high percentage of patients with CKF, due to the occurrence of cardiovascular comorbidities, take medications such as beta-blockers and diuretics whose most common side effect is erectile dysfunction. but, replacing it with other types of drugs does not appear to result in significant improvements of erectile function (13). An impaired synthesis of erythropoietin, very common in end-stage CKF patients, as is well known, produces anemia, causing, among other side effects, a low flow of oxygen in the corpora cavernosa; this results in a reduced synthesis of nitric oxide and increased production of contractile factors of endothelial origin, leading to an augmentation of smooth muscle tone and consequently a possible impairment of the mechanism of erection (14). Finally, the psychogenic component must not be ignored since patients on dialysis often suffer from anxiety, low self-esteem and chronic fatigue: these factors can lead to a reduction in sexual interest $(15,16)$. Due to all of the aforementioned possibilities, it is not surprising that the prevalence rate of erectile dysfunction in dialyzed patients could be as high as $80 \%$. In kidney transplanted patients, the prevalence of erectile dysfunction remains high, occurring in around $65 \%$ of cases and hypogonadism is also a frequent occurrence. The protracted uremic condition before the transplant is not only due to a functional damage but also to an anatomical damage to the delicate hypothalamic-pituitary-gonadal axis $(17,18)$. Biopsies performed on transplanted patients in testicular tissue, showed abnormalities of number and morphology of Leydig cells (17). Other authors, instead, have focused their attention on immunosuppressive therapy: a study by Lee showed that the sirolimus (an immunosuppressant drug often used in combination with calcineurin inhibitors in renal transplant) results in a significant decrease in serum concentrations of testosterone (18). It was also postulated that the cyclosporin forms adversely affect the production of nitric oxide, an essential substrate in the complex mechanism of erection (19). So it is possible that the immunosuppressive therapy in transplant patients helps to maintain the endothelial and gonadic dysfunction that the previous uremic state had produced. A final possible explanation for the ED in the transplanted patients is related to surgical transplant procedures: according to a study published by ElBahnasawy one internal iliac artery ligation without further external iliac artery terminal anastomosis results in a significant reduction of blood flow, negatively impacting penile erectile function (20).

\section{Objective}

The objectives of this study are as follows:

- The evaluation of the prevalence of sexual dysfunction (erectile dysfunction and hypogonadism) in male patients with end stage chronic renal failure on hemodialysis;

- The evaluation of the prevalence of sexual dysfunction (erectile dysfunction and hypogonadism) in male patients with end stage renal failure after kidney transplantation;

- The searching for factors predisposing to erectile dysfunction, with particular attention to hormones, in male patients with end stage chronic renal failure, on dialysis or after renal transplantation.

\section{MATERIALS AND METHOdS}

The study was conducted during the period between December 2010 to December 2011, at the University Hospital A. Gemelli, in the Department of Urology, Department of Transplant Surgery and Center for Hemodialysis. It involved a total of 95 patients aged between 20 and 65 years with severe chronic renal fail- 
ure, divided into two groups: one group of 44 patients who had been undergoing dialysis for more than a year and another consisting of 51 patients that recevied a kideny transplant more than 6 months before. Clinical information for patients in both groups was recorded (age, start of dialysis treatment/duration of transplantation, pathology that led to the CKF, comorbidity, drug treatment). All patients were given IIEF5 questionnaire, consisting of 5 questions. This was proposed by Rosen in 1997 and is widely known and used for the evaluation of the degree of erectile dysfunction (ED) (21). The score is recorded between a range of 2 and 30. Four categories can be identified depending on the score: the absence of disease (score 26-30), mild ED (17-25), moderate ED (11-16), severe ED $(<10)$. The study considered all patients with ED with a score less than or equal to 25. We also performed a blood test on all patients in order to measure total and free testosterone and prolactin. A normal range of prolactin was defined as $3.5-15.5 \mathrm{ng} / \mathrm{ml}$; from 2.50 to $8.4 \mathrm{ng} / \mathrm{ml}$ for total testosterone; from 2.50 to $8.4 \mathrm{ng} / \mathrm{ml}$ for free testosterone.

An informed consent was obtained from all patients.

\section{Statistical analysis}

For both groups we calculated the prevalence of hypogonadism and ED, which was in turn stratified by age and severity. Then, within the two groups (post-dialysis and transplant patients), some clinical features were compared along with laboratory records among patients presenting ED and those who did not presented it. The statistical relationships between ED and clinical-laboratory characteristics were evaluated with Student $t$ test for quantitative variables and chi-square test for qualitative variables. A $\mathrm{p}$ value $<0.05$ was considered statistically significant. Only those statistically significant factors at univariate analysis were further studied in a multivariate analysis. Statistical analysis was performed using the SPSS 14.0 system.

\section{Results}

In the group of dialyzed patients 44 men in total were recruited, the average age of the sample was 49 years. The ED was found in 31 patients, representing 70\% of the sample. Of these patients 7 (16\%) reported mild ED, $10(22 \%)$ moderate ED, and 14 (32\%) severe ED (Figure 1).

Patients older than 50 represent $61 \%$ of the total number of patients suffering from ED while representing just $31 \%$ of patients not suffering from $\mathrm{ED}, \mathrm{p}=0.006$. There is also a high prevalence of diabetes in those who suffer from ED compared with those who do not (39\% of the total number of patients suffering from ED versus $15 \%$, of the total number of patients not suffering, $\mathrm{p}=$ 0.014). The other clinical characteristics (duration of dialysis, use of beta-blockers), although presenting minimal difference between the two subgroups examined, do

Table 1.

\section{Table 2.}

Figure 1.

Prevalence of ED in patients with CKF on dialysis.

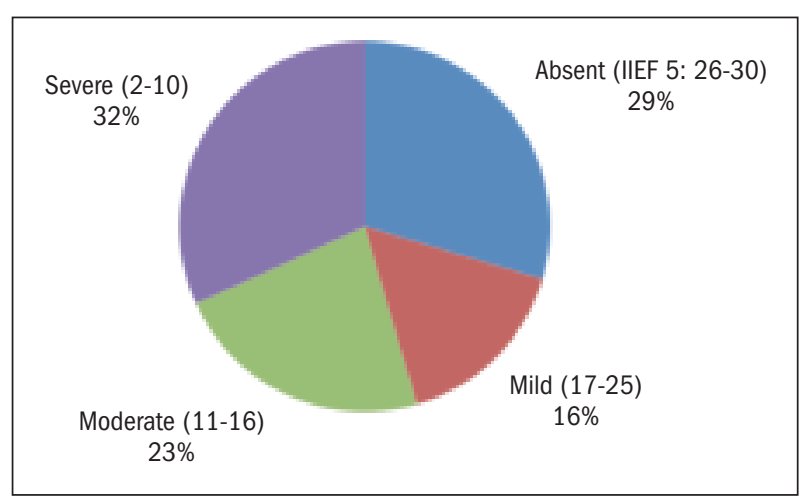

not reach the threshold of statistical significance. Among the laboratory parameters, hyperprolactinemia is present in $23 \%$ of patients, but without significant differences between the two subgroups. With regard to testosterone, as many as $59 \%$ of the patients had serum values below $250 \mathrm{ng} / \mathrm{dl}$ with a significant difference between those suffering from ED and those not (65\% of the total number of patients suffering from ED versus $46 \%$, of the total number of patients not suffering, $\mathrm{p}=0.019$ ) (Table 1 ). Among the considered factors, those which significantly correlated with ED based on a univariate analysis were the following: being older than 50 years of age, diabetes and a condition of hypotestosteronemia. These considerations are confirmed after a multivariate analysis (Table 2).

Clinical and laboratory characteristics of the sample.

\begin{tabular}{|c|c|c|c|c|}
\hline $\begin{array}{l}\text { Clinical-laboratory } \\
\text { characteristics }\end{array}$ & $\begin{array}{c}\text { Total patients } \\
n=44\end{array}$ & $\begin{array}{l}\text { Patients with ED } \\
\qquad n=31\end{array}$ & $\begin{array}{l}\text { Patients without ED } \\
\qquad n=13\end{array}$ & $\mathrm{p}$ \\
\hline Age $>50$ years & $23(52 \%)$ & $\begin{array}{c}19 \text { (61\% of ED } \\
\text { patients) }\end{array}$ & $\begin{array}{c}4 \text { (31\% of no-ED } \\
\text { patients) }\end{array}$ & 0.006 \\
\hline Diabetes & $14(31 \%)$ & $\begin{array}{c}12 \text { (39\% of ED } \\
\text { patients) }\end{array}$ & $\begin{array}{c}2 \text { (15\% of no-ED } \\
\text { patients) }\end{array}$ & 0.014 \\
\hline $\begin{array}{l}\text { Duration of dialysis } \\
\text { in months * }\end{array}$ & $65.2(52.4)$ & $63.1(50.9)$ & $67.3(54.3)$ & 0.72 \\
\hline Taking beta-blockers & $33(75 \%)$ & $\begin{array}{c}24 \text { (77\% of ED } \\
\text { patients) }\end{array}$ & $\begin{array}{c}9 \text { (69\% of no-ED } \\
\text { patients) }\end{array}$ & 0.66 \\
\hline $\begin{array}{l}\text { Hypotestosteronemia } \\
\text { (Free } \mathrm{T}<40 \mathrm{pg} / \mathrm{ml} \text { ) }\end{array}$ & $26(59 \%)$ & $\begin{array}{c}20 \text { (65\% of ED } \\
\text { patients) }\end{array}$ & $\begin{array}{c}6 \text { (46\% of no-ED } \\
\text { patients) }\end{array}$ & 0.019 \\
\hline $\begin{array}{l}\text { Hyperprolactinemia } \\
\text { (PRL > } 15.5 \mathrm{ng} / \mathrm{ml} \text { ) }\end{array}$ & $11(25 \%)$ & $\begin{array}{c}8 \text { (26\% of ED } \\
\text { patients) }\end{array}$ & $\begin{array}{c}3 \text { (23\% of no-ED } \\
\text { patients) }\end{array}$ & 0.53 \\
\hline
\end{tabular}

Results of multivariate analysis for risk factors for ED in patients with CKF on dialysis.

\begin{tabular}{|lccc|}
\hline Risk factors for ED & OR & IC 95\% & p \\
\hline Age $>50$ years & 7.221 & 1.826 to 29.385 & 0.004 \\
\hline Diabetes & 6.139 & 1.298 to 31.659 & 0.023 \\
\hline Hypotestosteronemia (fT < 40 pg/ml) & 6.456 & 1.437 to 40.871 & 0.031 \\
\hline OR: odds ratio; IC: interval confidence 95\%. & & & \\
\hline
\end{tabular}


Figure 2.

Prevalence of ED in CKF patients after kidney transplantation.

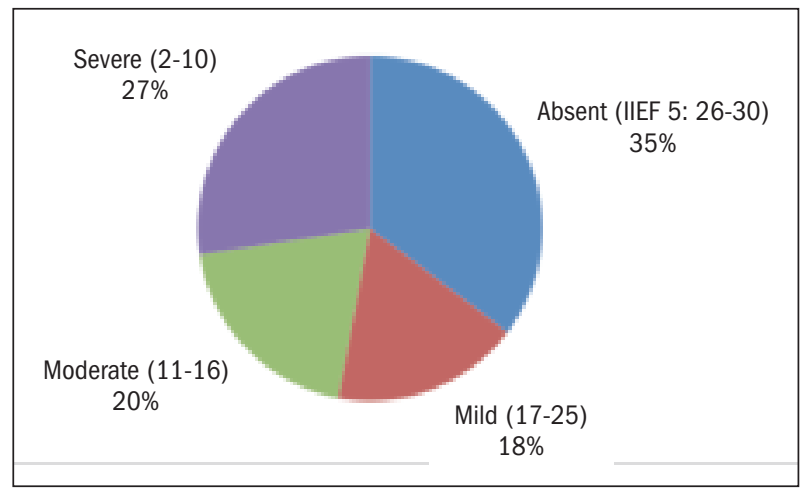

In the group of 51 patients with end stage CKF, who received renal transplantation from over a year, the average age stood at 47 years, DE was found in 33 patients (65\%). Out of them in 9 (18\%) DE proved to be mild, in $10(20 \%)$ moderate ED and in $14(27 \%)$ severe ED (Figure 2).

Through the evaluation of the clinical and laboratory characteristics of this second group of patients, it becomes clear that in the cases older than 50 years of age (51\% of the sample) there is a significant risk factor for the emergence of ED. There are 22 (67\%) who are over fifty, while in this subgroup four are not affected, accounting for only $22 \%(p=0.004)$. Diabetes, that in the dialysis group continues to be a statistically significant factor for the onset of ED ( $p=0.01)$, seems to play a significant role in the etiopathogenesis of ED in post-transplant, that did not depend on duration of transplantation and the possible use of betablockers. Turning to the evaluation of the hormone profile, hyperprolactinemia was present in $20 \%$ of the sample without significant differences between the two subgroups. However the most interesting result is that relative to the hypotestosteronemia which is predicated on having a prevalence of less than or equal to the group of dialysis $37 \%$ and also does not appear statistically significant correlated with the onset of ED $(\mathrm{p}=0.12)$ (Table 3$)$.

Age > 50 years and diabetes remain as the only statistically significant risk factors for the onset of ED in the group of transplant patients. The data was also confirmed after performing a 'multivariate analysis (Table 4).

\section{Discussion}

Erectile dysfunction in patients treated with dialysis for end-stage chronic kidney failure has a particularly high prevalence. The first epidemiological studies have been carried on since the early 70's by Abram (22). Over the years many others have been conducted,

Table 3.

Table 4. including Fletcher's (23), all of which indicated a prevalence rate above $50 \%$, varying between $63 \%$ and $81 \%$. In our study the prevalence of ED amongst patients on dialysis amounted to $70 \%$.

This shows that despite the clear improvement of therapy for end-stage kidney failure over the years, the prevalence of ED has remained high. Age was always considered as the major risk factor for the onset of ED and the concept is also valid for the patients on dialysis. In our study the mean age of patients without ED stands at 43 years. On the other hand, the average age is 54 in patients with ED. In this study therefore, patients over fifty have a 7.2 times greater risk of developing ED than younger individuals. However, if the data obtained in this study were to be compared with the data from other studies, in a sample of individuals in apparent good health, the average age of onset of ED is 5 years lower ( 54 vs 59 years) and severe forms of ED are 50\% more. Therefore the end-stage chronic renal failure has to be considered a factor that accelerates and exacerbates the pathological mechanisms responsible for the appearance of ED that develops normally with age.

In our study, as previously published (24), another significant risk factor is diabetes, which is the cause that leads a kidney disease patient to dialysis, and also the main responsible for the onset of ED. It is important to point out that diabetes is able to determine the onset of ED regardless of the presence or absence of diabetic nephropathy. In patients with end-stage CRF and diabetes, it is still uncertain whether the ED appears before or after the beginning of dialysis treatment.

With regard to the duration of dialysis treatment in our

Characteristics of clinical laboratory sample.

\begin{tabular}{|c|c|c|c|c|}
\hline $\begin{array}{l}\text { Clinical-laboratory } \\
\text { characteristics }\end{array}$ & $\begin{array}{l}\text { Total patients } \\
\quad \mathrm{n}=\mathbf{5 1}\end{array}$ & $\begin{array}{l}\text { Patients with ED } \\
\qquad n=33\end{array}$ & $\begin{array}{l}\text { Patients without ED } \\
\qquad n=18\end{array}$ & p \\
\hline Age $>50$ years & $26(51 \%)$ & $\begin{array}{c}22 \text { (61\% of ED } \\
\text { patients) }\end{array}$ & $\begin{array}{c}\text { (22\% of no-ED } \\
\text { patients) }\end{array}$ & 0.004 \\
\hline Diabetes & $15(29 \%)$ & $\begin{array}{c}13 \text { (39\% of ED } \\
\text { patients) }\end{array}$ & $\begin{array}{c}2 \text { (11\% of no-ED } \\
\text { patients) }\end{array}$ & 0.010 \\
\hline $\begin{array}{l}\text { Duration of } \\
\text { transplantation in years * }\end{array}$ & * $7.2(5.6)$ & $7.4(5.9)$ & $7.0(5.4)$ & 0.82 \\
\hline Taking beta-blockers & $35(69 \%)$ & $\begin{array}{c}24 \text { (72\% of ED } \\
\text { patients) }\end{array}$ & $\begin{array}{c}11 \text { (61\% of no-ED } \\
\text { patients) }\end{array}$ & 0.57 \\
\hline $\begin{array}{l}\text { Hypotestosteronemia } \\
\text { (Free } \mathrm{T}<40 \mathrm{pg} / \mathrm{ml} \text { ) }\end{array}$ & $19(37 \%)$ & $\begin{array}{c}13 \text { (39\% of ED } \\
\text { patients) }\end{array}$ & $\begin{array}{c}6 \text { (33\% of no-ED } \\
\text { patients) }\end{array}$ & 0.012 \\
\hline $\begin{array}{l}\text { Hyperprolactinemia } \\
\text { (PRL> } 15.5 \mathrm{ng} / \mathrm{ml} \text { ) }\end{array}$ & $10(20 \%)$ & $\begin{array}{c}7 \text { (21\% of ED } \\
\text { patients) }\end{array}$ & $\begin{array}{c}3 \text { (17\% of no-ED } \\
\text { patients) }\end{array}$ & 0.36 \\
\hline
\end{tabular}

Results of multivariate analysis for risk factors for ED in CRF patients after kidney transplantation.

\begin{tabular}{|lccc|}
\hline Risk factors for ED & OR & IC 95\% & p \\
\hline Age $>50$ years & 7.823 & 1.724 to 26.384 & 0.005 \\
\hline Diabetes & 6.755 & 1.128 to 30.054 & 0.019 \\
\hline OR: Odds ratio; IC: interval confidence 95\%. & & & \\
\hline
\end{tabular}


study, it affects neither the appearance nor the development of ED. This conclusion is supported by numerous studies in the literature (25). There is, however, a prospective study carried out by Capotondo in 1990, which shows an improvement of ED in the first three months of dialysis treatment, before returning to previous levels (26). Wein and Van Arsdalen have identified a list of drugs most commonly used by the general population that may be able to determine ED, some of which are frequently used in dialysis patients (27).

In our study, the focus was on beta-blockers, but no significant correlation between drug intake and onset of ED was found. In the literature there is only one study that demonstrates that the use of beta blockers is a significant risk factor for developing ED in dialyzed patients.

As for the evaluation of the hormone profile, a condition of hyperprolactinemia was found in $25 \%$ of the sample, according with the data in the literature ranging between 20 and $40 \%$. This however does not seem to affect the appearance of ED, but we need to point out the existence of studies which show that there exists a connection between the condition of hyperprolactinemia and decreased libido (28). A condition of important hypotestosteronemia ( $\mathrm{T}<250 \mathrm{ng} / \mathrm{dl}$ ) was seen in almost $60 \%$ of the sample, which is quite concordant with the literature (29).

However, it remains disputed why this condition appears. According to some authors, the reason might be the uremia, that, like with other organs (eg, uremic cardiomyopathy, uremic gastritis), leads to a dysfunction of the complex mechanisms of regulation of the hypothalamic-pituitary-gonadal axis, caused especially by changes in the opioid pathway (30); according to other authors the substances used in dialysis membranes produce a functional and histological change in the gonads (31). A third hypothesis is based on the loss of most steroid precursors during dialysis procedures. Finally there is one last hypothesis that claims that the decreased blood level of zinc may be the cause (32).

Our study also shows that hypotestosteronemia is an effective risk factor for the onset of ED. The data in the literature concerning this statement are very discordant and very often this is determined by the different value of testosterone serum concentrations considered pathological by different authors. In recent years, however, the tendency is to reaffirm an important role of testosterone in erectile mechanisms: in fact, there are frequent cases of ED refractory to PDE-5 inhibitors that happen to be cases of unknown hypogonadism (33).

The records obtained from end-stage CKD patients treated with renal transplantation, are similar to those obtained from the group of patients undergoing dialysis. Also in this group the prevalence of ED is higher, it appears earlier and is more severe than in the group of patients not affected by CKF. We would underline that there is a slightly lower prevalence (65\% vs $70 \%$ ) of ED in transplanted patients compared with dialyzed ones, but the difference is not so blatant and numerous comparative studies showed that the prevalence of ED before and after renal transplantation remains the same or the improvement is only limited to a small percentage of cases $(34,35)$.
As well as in dialyzed patients, in transplanted patients advanced age and diabetes are major risk factors for the development of ED. Beta blockers intake and hyperprolactinemy do not seem to affect the onset of ED.

The new element is represented by a reduction in the prevalence of hypotestosteronemia (37\% vs 59\%).

This may suggest, on one hand, that the uremia improvement obtained by transplant solves at least in part the condition of hypogonadism, and on the other hand that dialysis treatment is actually one of the causes of the hypotestosteronemia.

Hypotestosteronemia still has a much higher prevalence in these patients rather than in subjects in apparent good health (37\% vs $12 \%$ ) of the same age. This is probably due to the fact that uremia and dialysis treatment produce not only a functional damage, but also an anatomic chronic damage at gonads. Another hypothesis is that the immunosuppressive therapy to which the transplanted patients are subjected, determines a disendocrine disease preventing at least in part, the resolution of the hypogonadism. In the end, the hypotestosteronemia does not appear to be a significant risk factor for the onset of ED in the transplanted patients therefore, probably, the ED is caused by the vascular and neuropathic chronic damage produced by pre-existing chronic uremia. Many recent publications have pointed out the usefulness and the safety of the treatment.

A study by Sharma in 2006 and one by Cofan in 2002 have shown effectiveness of therapy in approximately $85 \%$ of the subjects and at the same time no change in blood concentration of calcineurin inhibitors $(36,37)$.

In patients on hemodialysis, as well as in transplanted patients, the elective drugs for treatment of ED are the PDE5 inhibitors.

A review of the 2006 shows their effectiveness and safety. However, the number of patients not responding to the therapy is higher than that found in transplant recipients. As our study demonstrated, hypogonadism is a major risk factor for ED in dialyzed patients.

For this reason, in refractory cases in which the hypotestosteronemia is diagnosed, it is necessary to support a PDE5 inhibitor therapy with transdermal hormone replacement therapy $(5 \mathrm{mg} /$ day) or intramuscular (250 mg every 3-6 weeks). Recent studies in fact show a synergistic role of testosterone and PDE-5 inhibitors: in fact, testosterone induces an increased expression of iNOS in the corpora cavernosa.

\section{Conclusions}

ED in patients with end stage CKF continues to have a strong prevalence, in cases both where the patients are undergoing dialysis or have received transplants. In the literature this issue is often not considered, or sufficiently so, with the direct consequence that the ED often ends up being misunderstood and therefore not treated in these patients. In our experience during this study it is evident that both patients and their physicians maintain a certain reticence on this issue, even though the patients affected by ED say that this condition greatly impacts their quality of life.

Our advice therefore would be to practice all the strate- 
gies (reduction of risk factors and pharmacological approach) that could counteract the ED. Age, obviously, is not a modifiable factor, but an effective diabetic control is possible, and both the kidney basic functionality and erection would benefits from that. Our study also shows that the hypotestosteronemia is a genuine risk factor for the onset of ED in patients with end-stage chronic renal failure. Based on the records of prevalence of hypogonadism which is significantly lower among transplant recipients, the kidney transplantation appears to have a protective role of the sexual capabilities of these patients.

This may suggest, on one hand that the improvement of uremia obtained by transplant solves at least in part the condition of hypogonadism, or on the other, that dialysis treatment is actually one of the causes of the hypotestosteronemia.

Finally, we pointed out that the therapy of hypogonadism, not only helps to solve the ED so improving the quality of life for patients, but also could increase life expectancy. In fact, there is increasingly more scientific evidence indicating that low testosterone serum level correlates with increased cardiovascular accidents, increased central obesity, metabolic syndrome, bone fragility which would reduce life expectancy.

\section{REFERENCES}

1. Leny NB. Sexual adjustments to maintenance dialysis and renal transplantation. National survey by questionnaire. Preliminary results. Trans Am Soc Artif Int Organs. 1973; 19:138-143.

2. Procci WR, Goldstein DD, Adelstein J, Massry SG. Sexual dysfunction in the male patient with uremia. A reappraisal. Kidney Int. $1981 ; 19: 317-323$

3. Toorans AWFT, Janssen E, Laan E, et al. Chronic renal failure and sexual functioning: clinical status versus objectively assessed sexual response. Nephrol Dial Transplant. 1997; 12:2654-2663.

4. Bergandahl M, Evans WS, Veldhuis JD. Current concepts on ultradian rhythms of luteinizing hormone secretion in the human. Hum Reprod Update. 1996; 2:507-518.

5. Steward-Bentley M, Gans D, Horton R. Regulation of gonadal function in uremia. Metabolism 1974; 23:1065-1072.

6. Coppola A, Cuomo G. Pituitary testicular evaluation in patients with chronic renal insufficiency in haemodialysis treatment. Minerva Med. 1990; 81F 461-464.

7. Handelsman DJ, Dong Q. Hypothalamic-pituitary-gonadal axis in chronic renal failure. Endocr Metab Clin North Am. 1993; 22:145-161.

8. Chryssicopoulos A, Koutsikos D, Kapetanaki A, et al. Evaluation of the hypothalamic-pituitary axis in uraemic males using dynamic tests. The possible role of testicular inhibin. A preliminary report. Renal Fail. 1996; 18:911-921.

9. Bancroft J. Human Sexuality and its Problems, ed 2. Churchill Livingstone, Edinburgh, 1989; 12-145.

10. Saenz de Tejada I, Goldstein I, Azadzoi K, et al. Impaired neurogenic and endothelium-mediated relaxation of penile smooth muscle from diabetic men with impotence N Engl J Med. 1989; 320:1025-1030.

11. Campese VM, Procci WR, Levitan D, et al. Autonomic nervous system dysfunction and impotence in uremia. Am J Nephrol. 1982; 2:140-143.

12. Linder A, Charra B, Sherrar D, et al. Accelerated atherosclerosis and prolonged maintenance hemodialysis. N Engl J Med. 1974; 290:697-701.

13. Kaufman JM, Hatzichristou DG, Mulhall J, et al. Impotence and chronic renal failure. A study of the hemodynamic pathophysiology. J Urol, 1994; 151:612-618.

14. Virag R, Bouilly P, Frydman D. Is impotence an arterial disease? Lancet. 1985; 1:181-184.

15. Kim N, Vardi Y, Padma-Nathan H, et al. Oxygen tension regulates the nitric oxide pathway. Physiological role in penile erection. $J$ Clin Invest. 1993; 19:437-442.

16. Janssen. E, Everaerd W, Van Lunsen et al. Validation of a psychophysiological waking erectile assessment (WEA) for the diagnosis of the male erectile disorder. Urology. 1994; 43:686-695.

17. Lim VS. Reproduction function in patients with renal insufficiency. Am J Kidney Dis. 1987; 9:363-367.

18. Rebollo P, Ortega F, Valdes C, et al. Factors associated with erectile dysfunction in male kidney transplant recipients. Int J Impot Res. 2003; 15:433.

19. Wong JA, Lawen J, Kiberd B, et al. Prevalence and prognostic factors for erectile dysfunction in renal transplant recipients Can Urol Assoc J. 2007; 1:383-387.

20. El-Bahnasawy MS, El-Assmy A, El-Sawy E, et al. Critical evaluation of the factors influencing erectile function after renal transplantation. Int J Impot Res. 2004; 16:521-6.

21. Rosen RC, Cappelleri JC, Smith MD, et al. Development and evaluation of an abridged, 5-item version of the International Index of Erectile Function (IIEF-5) as a diagnostic tool for erectile dysfunction. Int J Impot Res. 1999; 11:319-26.

22. Abram HS, Hester LR, Sheridan WF, Epstein GM. Sexual functioning in patients with chronic renal failure. J Nerv Ment Dis. 1975; 160:220-6

23. Rodger RS, Fletcher K, Dewar JH, et al. Prevalence and pathogenesis of impotence in one hundred uremic men. Uremia Invest. 1984-1985; 8:89-96.

24. Glass CA, Fielding DM, Evans C, Ashcroft JB. Factors related to sexual functioning in male patients undergoing hemodialysis and with kidney transplants. Arch Sex Behav. 1987; 16:189-207.

25. Cerqueira J, Moreas M, Glina S. Erectile dysfunction: prevalence and associated variables in patients with chronic renal failure. Int $J$ Impot Res. 2002; 14:65-71.

26. Capotondo L. Replacement of sexual function by dialysis Am J Physiol. 1992; 262:F275-F287.

27. Van Arsdalen KN and Wein AJ. Drug induced sexual dysfuntion in older men. Geriatrics. 1984; 39:63-70.

28. Perryman RL, Thorner MO. The effects of hyperprolactinemia on sexual and reproductive function in men. J Androl. 1981; 5:233.

29. Handelsman D. Hypothalamic-pituitary gonadal dysfunction in renal failure, dialysis and renal transplantation. Endocr Rev. 1985; 6:151-82.

30. Lim V, Fang V. Gonadal dysfunction in uremic men. A study of the hypothalamo-pituitary-tisticular axis before and after renal transplantation. Am J Med. 1975; 58:655-62 
31. Palmer BF. Sexual dysfunction in uraemia. J Am Soc Nephrol. 1999; 10:1381-8.

32. Hakim R, Depner T, Parker T. Adequacy of haemodialysis. Am J Kidney Dis. 1992; 20:107-123.

33. Penson DF, Ng C, Cai L, et al. Androgen and pituitary control of penile nitric oxide synthase and erectile function in the rat. Biol Reprod.1996; 55:567-574.

34. Peskircioglu L, Tekin MI, Demirag A, et al. Evaluation of erectile function in renal transplant recipients. Transplant Proc. 1998; 30:747-749.
35. Malavaud B, Rostaing L, Rischmann P, et al. High prevalence of erectile dysfunction after renal transplantation. Transplantation. 2000; 69:2121-2124.

36. Sharma RK, Prasad N, Gupta A, Kapoor R. Treatment of erectile dysfunction with sildenafil citrate in renal allograft recipients: a randomized, double-blind, placebo-controlled, crossover trial. Am J Kidney Dis. 2006; 48:128-33.

37. Cofán F, Gutiérrez R, Beardo P, et al. Interaction between sildenafil and calcineurin inhibitors in renal transplant recipients with erectile dysfunction Nefrologia. 2002; 22:470-6.

\section{Correspondence}

Michele Antonucci, MD (Corresponding Autor)

mic.antonucci@yahoo.it

Giuseppe Palermo, MD

Salvatore Marco Recupero, MD

Riccardo Bientinesi, MD

Nazario Foschi, MD

PierFrancesco Bassi, MD

Gaetano Gulino, MD

Department of Urology Clinic, Catholic University of S. Heart, Rome

Largo A. Gemelli 8, 00168 Rome, Italy

Fabrizio Presicce, MD

Urology, Policlinico S. Andrea, "La Sapienza” University, Rome 